\title{
Groundwater Vulnerability Assessment of the Tarkwa Mining Area Using SINTACS Approach and GIS*
}

\author{
${ }^{1}$ A. Ewusi, ${ }^{1}$ I. Ahenkorah and ${ }^{1}$ J.S.Y. Kuma \\ ${ }^{1}$ University of Mines and Technology, P.O. Box 237, Tarkwa, Ghana
}

Ewusi, A., Ahenkorah, I., and Kuma, J.S.Y. (2017), "Groundwater Vulnerability Assessment of the Tarkwa Mining Area Using SINTACS Approach and GIS”, Ghana Mining Journal, Vol. 17, No. 1, pp. 18 - 30.

\begin{abstract}
Groundwater vulnerability assessment to delineate areas that are susceptible to contamination from mining and anthropogenic activities has become an important element for resource management and landuse planning. In view of the extensive mining in the Tarkwa area, quality of groundwater has become an important issue. This study estimates aquifer vulnerability by applying the SINTACS model which uses seven environmental parameters to evaluate aquifer vulnerability and geographical information system (GIS) in the Tarkwa mining area. Sensitivity analysis has also been carried out to evaluate the relative importance of the model parameters for aquifer vulnerability. The SINTACS model results show that the intrusive rocks within the Tarkwaian and the Birimian rocks are dominated by very high vulnerability classes while the Banket Series is characterised by high vulnerability class. The Huni Sandstones have moderately high vulnerability. In addition, the Kawere Group and the Tarkwa Phyllites displayed medium vulnerability. Analysis from the variogram model shows that all parameters used in the SINTACS model have a strong spatial structure. From statistical analysis, depth to water parameter inflicted the highest impact on the vulnerability of the aquifer followed by effective infiltration, vadose zone media, soil media, aquifer media, topography and hydraulic conductivity in the order of decreasing impact. Sensitivity analysis indicated that the aquifer media, hydraulic characteristics and topography cause large variation in vulnerability index. Depth to water and effective infiltration were found to be more effective in assessing aquifer vulnerability.
\end{abstract}

Keywords: Groundwater, Vulnerability, Tarkwa, SINTACS, GIS

\section{Introduction}

Groundwater is a vital resource for potable water supply to the Tarkwa mining town. This is because most of the surface water bodies in the area are polluted as a result of illegal small scale mining activities popularly known as "galamsey". The area is also host to two large scale gold mining companies and one large scale manganese mining company. Generally, groundwater in hard-rock aquifers, particularly in mining areas are known to be vulnerable to quality problems that may have serious impact on human health (Smedley et al., 1995). Groundwater contamination occurs when chemicals from mining activities such as cyanide and mercury get into the groundwater and cause it to become unsafe and unfit for human use. There are many reported incidents of spillages and leakages of contaminants into groundwater as a result of mining and other anthropogenic activities. Naicker et al., (2003) reported that, groundwater within the Witwatersrand mining District of South Africa is heavily contaminated and acidified as a result of oxidation of pyrite $\left(\mathrm{FeS}_{2}\right)$ contained within the mine tailings dumps, and has elevated concentrations of heavy metals. Seepage from the Tailings Storage Facility (TSF) of Anglogold Ashanti Iduapriem Limited located in Tarkwa necessitated the closure of the facility (Anon., 2010).
Groundwater development in Tarkwa, have often been hampered among other problems by contaminants from mining activities, improper waste disposal, leakage of underground storage tanks, and seepage of agrochemicals from municipal and agricultural fields (Akabza, 2000). The Groundwater in the Tarkwa area therefore run a high risk of pollution with industrial chemical from mining, municipal, industrial, and domestic waste because of the high density of mining companies, intensive small scale mining activities and urbanisation. Pollutants released on the ground surface from mining activities may rapidly reach the aquifer and travel long distance in a very short time through preferential pathways (Tazioli et al., 1995). It is therefore, imperative to carry out an extensive groundwater vulnerability assessment in Tarkwa especially in the Tarkwain rocks which is the main target rock for mining in the area and to determine the tendency and likelihood for contaminants including harmful chemicals used in mining activities to reach the water table after introduction at the ground surface.

The objectives of this study are to assess the vulnerability of groundwater from selected boreholes in the Tarkwa area using an integration of SINTACS approach and Geographic Information System (GIS), produce a vulnerability map of the area using overlay analysis and kriging to highlight areas of very high, high, moderate, low and very low risk to contamination and to conduct 
sensitivity analysis on the effective and theoretical weight of the SINTACS parameters.

\subsection{Location and Accessibility}

Tarkwa is one of the landlocked municipal capitals in the Western Region of Ghana. It is located between latitude $4^{\circ} 0^{\prime} 0^{\prime \prime} \mathrm{N}$ and $5^{\circ} 40^{\prime} 0^{\prime \prime} \mathrm{N}$ and longitude $1^{\circ} 45^{\prime} 0^{\prime \prime} \mathrm{W}$ and $2^{\circ} 1^{\prime} 0 " \mathrm{~W}$ as shown (Fig. 1). The municipality has a total land area of $2354 \mathrm{~km}^{2}$ (Yankey et al., 2011). The Tarkwa-Nsuaem municipality is accessible by trunkroad and railway. The major road networks in the municipality links major regions such as Takoradi and Kumasi.

The Municipality is by way of transport infrastructure also linked with a single track rail with Tarkwa the main station on the Takoradi to Kumasi route.

\subsection{Topography and Drainage}

Tarkwa and its environs lie generally within mountain ranges covered by thick forest with a variety of fauna and flora. In some cases, the ranges are interspersed by undulating valley bottoms. Tarkwa township and its surrounding settlements are wedged between two long ranges of hills considered the two limbs of a gold mountain. These mountain ranges rise to an average of $300 \mathrm{~m}$ above sea level but can reach $335 \mathrm{~m}$. These evergreen mountain ranges are rich in biodiversity at least, before the unset of mining and with the numerous settlements in-between them present appealing aesthetic scenery. Unfortunately, these ridges are the main areas where gold is found, and they are targets for open pit mines (Akabzaa and Darimani, 2001).

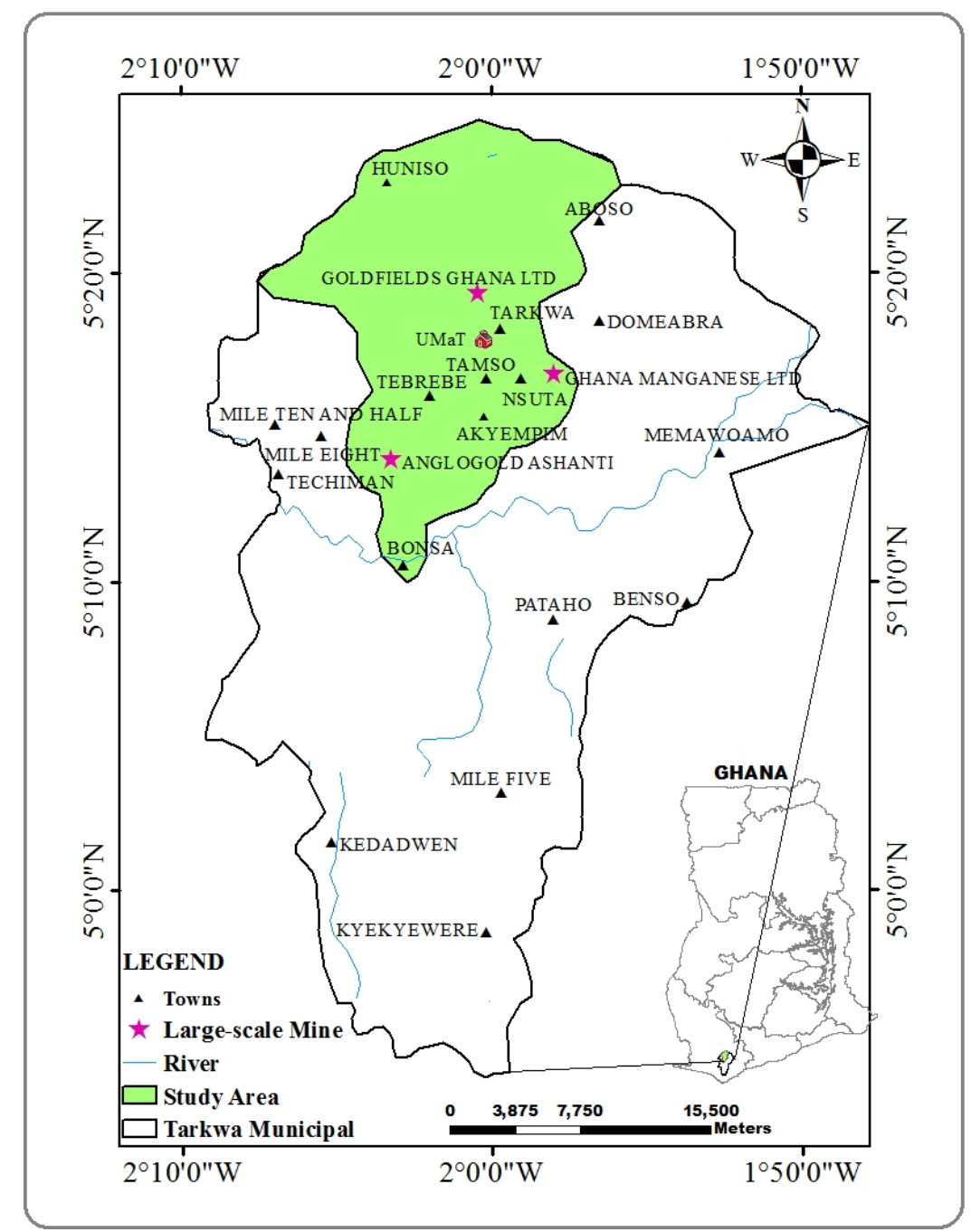

Fig. 1 Map of Tarkwa Nsueam Municipal Showing the Tarkwa Township 
Tarkwa presents a unique drainage system. The mountain ranges constitute the source of water for many of the rivers and streams in the area. The Tarkwa area is also part of an extensive drainage basin known as the Ankobra Basin comprising the Ankobra River and its tributaries. Rivers in the Tarkwa area take their source from the ridges within the mining concessions of the large scale mining companies operating open pit mines in the area. These rivers and their tributaries facilitate mining activities in the area particularly for galamsey operators by providing the water required for the processing of gold (Akabzaa and Darimani, 2001).

\subsection{Climate and Vegetation}

The area falls within the equatorial climatic zone, primarily the tropical rain forest zone of Ghana. The area has a mean annual rainfall in the range of $1500 \mathrm{~mm}$ and $1933 \mathrm{~mm}$ with most of the rains occurring from April to June and October to November giving it a bi-modal rainfall regime. Relative humidity for the area ranges from $70 \%$ to $90 \%$. The daily temperature ranges between $20{ }^{\circ} \mathrm{C}$ and $40{ }^{\circ} \mathrm{C}$ while the mean monthly temperature ranges from $24{ }^{\circ} \mathrm{C}$ to $30{ }^{\circ} \mathrm{C}$ (Akabzaa and Darimani, 2001).

The vegetation of the area consists of tropical rain forest characterised by rich undergrowth of climbers and shrubs of varying heights. The trees, which generally reach heights of between $15 \mathrm{~m}$ and $45 \mathrm{~m}$ are distributed mostly at the summit of hills where mining has not yet reached. Lack of protection from mining and lumber activities is primarily responsible for the present poor vegetation in the area. Where the area has been mined out, the vegetation consists of ferns and other shrubs which grow profusely on the hilly slopes (Akabzaa and Darimani, 2001).

\subsection{Geology and Hydrogeology}

The geological formations in the Municipality are mostly the Birimian and Tarkwaian rock formations. Tarkwa is located on the contact between the Tarkwaian rocks due west and older Birimian Supergroup of Ghana to the east (Eisenlohr and Hirdes, 1992). The Tarkwaian system is made up of a sequence of clastic sedimentary rocks, which comprises of sandstones, conglomerates and meta-sedimentary phyllites. It is spatially associated with 'belt' rocks of the Birimian. It is regarded as detritus of Birimian rocks and granitoids that was uplifted and eroded in the Eburnean event (Junner et al., 1942). The rocks of the Tarkwaian system as illustrated in Fig. 2 consist of the Kawere Group, the Banket Series, the Tarkwa Phyllite and the Huni Sandstone. The Kawere Group is the oldest group and the conglomerates consist of silicified Birimian greenstone and hornstone with minor jasper, quartz, quartz-porphyry, tourmaline-quartz rocks with Birimian phyllites and schists in a matrix with quartz, feldspar, chlorite, carbonate, epidote and magnetite (Junner et al., 1942). The Banket conglomerate consists of $90 \%$ quartz and the rest is Birimian schist, quartzite, hornstone, chert and gondite. The Tarkwa Phyllite consists of chloritoid and magnetite or hematite with sericite and chlorite. Huni Sandstone consists of variable amounts of feldspar, sericite, chlorite, ferriferous carbonate, magnetite or hematite and epidote (Junner et al., 1942; Kesse, 1985; Kuma and Younger, 2001).

The Birimian Supergroup consists of penecontemporaneous low-grade metamorphosed sedimentary and volcano-clastic rocks (Eisenlohr and Hirdes, 1992). In the Tarkwa area the rocks consist of phyllites and pyroclastics made of tuffs with interbedded mudstones which are intruded by andesitic and basaltic lavas. The metamorphosed rocks are tightly folded and fractured with a weathering profile of more than $100 \mathrm{~m}$ in some places (Junner et al., 1942).

The Tarkwaian and Birimian rocks of the area do not have adequate primary porosity. They are largely crystalline and inherently impermeable, unless fractured or weathered. Groundwater occurrence is therefore associated with the development of secondary porosity and permeability.

The zones of secondary permeability are often discrete and irregular and occur as fractures, faults, lithological contacts and zones of deep weathering (Kortatsi, 2002). Groundwater in the Tarkwa area is acknowledged to occur in two distinct hydraulically connected aquifer systems; an upper weathered zone aquifer and a deeper un-weathered aquifer or fractured zones and dyke contacts (Junner et al., 1942). The weathered zone aquifer is generally phreatic and the principal groundwater flow occurs where relic's quartz veins are more abundant. The regolith is generally dominated by clay and silt rendering the aquifer highly porous, with high storage but low permeability.

Thus, the aquifers are either unconfined or semiconfined depending on the clay and silt proportion. Aquifers are recharged by direct infiltration of precipitation through brecciated zones and the weathered outcrop (Kortatsi, 2002). Groundwater recharge and actual evapotranspiration have been estimated at between (11-17) \% and $54 \%$ respectively of annual rainfall (Kuma, 2007). 


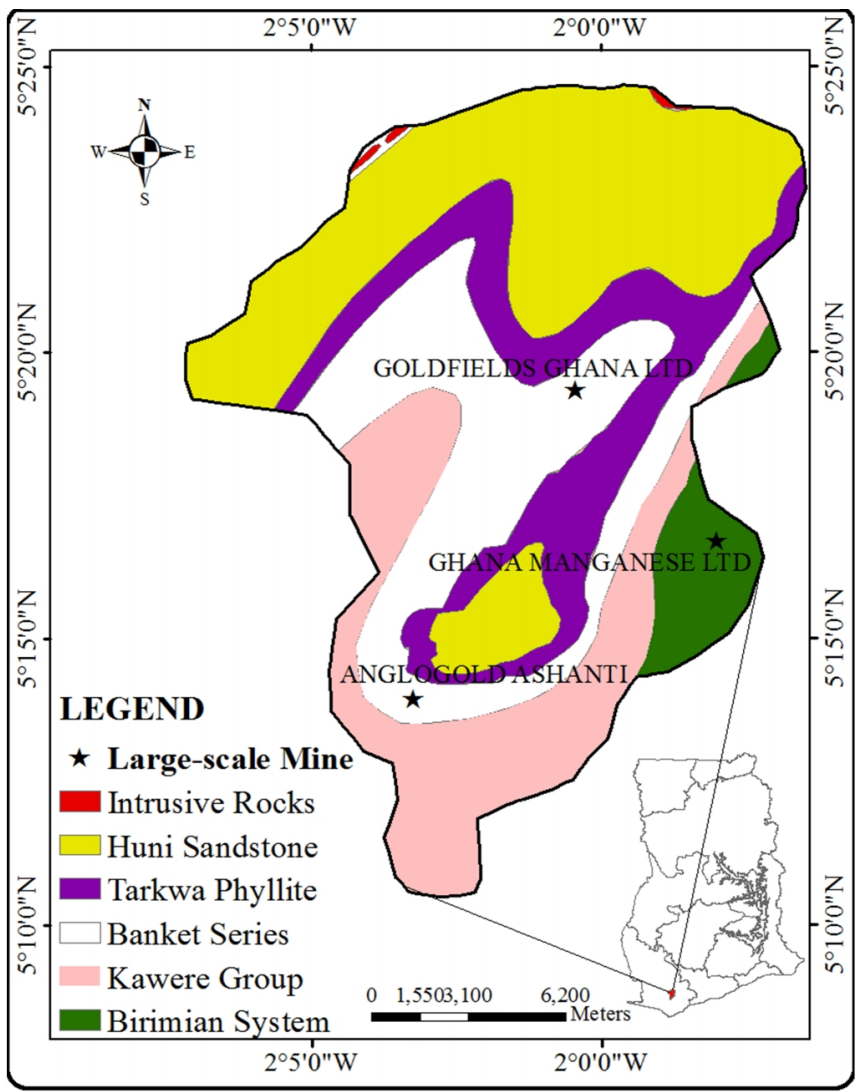

Fig. 2 Geological Map of the Study Area

\section{Resources and Methods Used}

\subsection{Source of Data}

Both primary and secondary data were used. The primary data was obtained by using a handheld Global Position System (GPS) to map contaminant sources in the study area. Borehole logs, static water levels, aquifer yields, landuse and soil media within the various rock types found within the Tarkwa area were obtained from the Ghana Water Company Ltd (GWCL), Ghana Meteorological Agency (GMA) and Community Water and Sanitation Agency (CWSA). The data used for creating the SINTACS model are summarised in Table 1.

\subsection{SINTACS Approach}

The SINTACS model is an updated model of the US DRASTIC method and shows vulnerability index using the seven hydrological parameters such as water table depth (S), net recharge (I), unsaturated zone (vadose zone) $(\mathrm{N})$, soil media $(\mathrm{T})$, aquifer media (A), hydraulic conductivity (C) and topographic slope $(\mathrm{S})$. The SINTACS approach is preferred over other methods because of low cost, data sets availability, geology and the peculiar hydrological environment. Several types of data were used to construct thematic layers of the seven model parameters. The intrinsic vulnerability values obtained indicate the potential contamination that may occur. The higher the vulnerability index, the higher the probability of contamination (Civita and De Maio, 1997).

The well location vector layer was prepared based on the GPS survey during primary data collection and the spatial distribution map of water table was obtained through Inverse Distance Weighting (IDW) interpolation technique.

Depth to water table was obtained from information on boreholes in the area. Effective infiltration plays a significant role in aquifer vulnerability assessment. It drags down surface pollutant into dilution, first during the travel through the unsaturated zone and then within the saturated zone. Direct infiltration is the only or widely prevalent component of the net recharge in all the areas where there are no interflow linking aquifers or surficial water bodies or no irrigation practices using large water volumes.

The unsaturated zone is one of the important parameters in vulnerability assessment and hence a higher weightage is assigned to it. The unsaturated zone map for the study area was prepared from the well lithological data acquired from Community Water and Sanitation Agency (CWSA). 
Table 1 Data used for creating the SINTACS Model

\begin{tabular}{|c|c|c|c|c|c|c|c|}
\hline \multirow[b]{2}{*}{ Rock Type } & \multicolumn{7}{|c|}{ Average values for the various SINTACS Parameters } \\
\hline & $\mathbf{S}(\mathbf{m})$ & I (mm/yr) & $\mathbf{N}$ & $\mathbf{T}$ & $\mathbf{A}$ & $\mathrm{C}\left(10^{-6}\right)$ & $\mathbf{S}(\%)$ \\
\hline $\begin{array}{l}\text { Huni } \\
\text { Sandstone }\end{array}$ & 5.93 & 100 & Sandstone & Silty-Sand & Sandstone & 1.6 & 10 \\
\hline $\begin{array}{l}\text { Tarkwa } \\
\text { Phyllite }\end{array}$ & 3.57 & 150 & Phyllite & Laterite & $\begin{array}{l}\text { Fresh/ } \\
\text { Weathered } \\
\text { Phyllite }\end{array}$ & 3.5 & 20 \\
\hline Banket Series & 4.93 & 299 & $\begin{array}{l}\text { Quartzite/ } \\
\text { Conglomerate }\end{array}$ & $\begin{array}{l}\text { Silty-Sand/ } \\
\text { Laterite }\end{array}$ & $\begin{array}{l}\text { Fractured } \\
\text { Quartzite/ } \\
\text { Conglomerate }\end{array}$ & 4.93 & 25 \\
\hline Kawere Group & 8 & 70 & Conglomerate & Silt Sand & Conglomerate & 0.72 & 12 \\
\hline $\begin{array}{l}\text { Birimian } \\
\text { System// } \\
\text { Intrusives }\end{array}$ & 3.5 & 200 & $\begin{array}{l}\text { Fissured } \\
\text { Volcanic } \\
\text { Rocks }\end{array}$ & Silt & $\begin{array}{l}\text { Fissured } \\
\text { Volcanic } \\
\text { Rocks }\end{array}$ & 0.88 & 10 \\
\hline
\end{tabular}

The soil media has an important role in assessing intrinsic vulnerability of groundwater. Soil has the ability to restrict the vertical flow of contamination to the subsurface. The textural characteristic of soil has capacity to control intrinsic vulnerability of groundwater. The ratings are assigned to soil layer as per the infiltration capacity.

The aquifer media (A) has the potential for storage of water. Rocks (consolidated and unconsolidated) can act as an aquifer media. In the presence of fractures or openings in rocks the permeability value differs.

Hydraulic conductivity controls the rate at which groundwater will flow under a given hydraulic gradient. In the SINTACS assessment context, the hydraulic gradient and the flux cross section being equal, this parameter determines the aquifer unit yield and flow velocity that go toward the effluences or the tapping work that indicates risk targets.

The topographic slope is an important factor in vulnerability assessment because it determines the amount of surface runoff that is produced, the precipitation rate and displacement velocity of the water over the surface being equal. A high rating is assigned to slight slopes i.e. to surface zones where a pollutant may be less displaced under gravity action or even stop in the outlet place favouring percolation. The slope may be a genetic factor due to the type of soil and its thickness, and can indirectly determine the attenuation potential of the hydrogeological system.

\subsection{SINTACS Parameter Map Generation Using ArcGIS}

Arc Info 10 from ArcGIS software was used to create layers for each of the seven SINTACS parameters using Geostatistical Analyst Tool from the ArcGIS through interpolation (using Kriging and Co-Kriging) to create vector surface layer. This was then converted to raster surface layer through classification, where the ratings were assigned to the parameters. The classified raster layer was converted into reclassify raster layer by the Reclass and then Reclassify under the Spatial Analyst Tools. This was used for overlay analysis and Weighted Overlay as shown in Fig. 3.

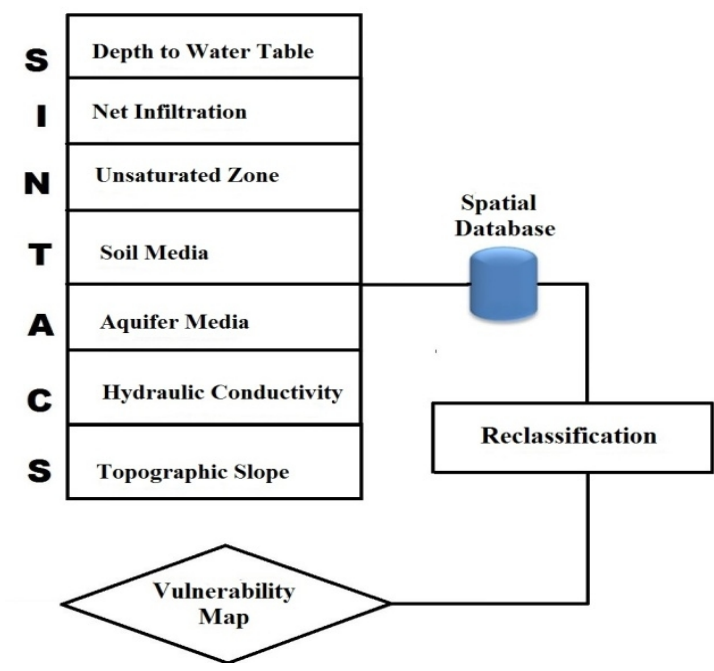

Fig. 3 Flow Chart of the SINATACS Parameters used to produce Vulnerability Map

The SINTACS index was calculated using Eqn. 1 in the GIS environment to map the groundwater vulnerability of the study area.

$$
\mathrm{I}_{\text {SINTACS }}=\sum_{\mathrm{J}=1}^{7} \mathrm{P}_{\mathrm{J}} \mathrm{W}_{\mathrm{J}}
$$

where

$P_{\mathrm{J}}$ is the score of each parameters

$\mathrm{W}_{\mathrm{J}}$ is the relative weight.

The data extracted from the various data sets were compliled in a spread sheet using Microsoft Excel software. 
This was then converted into a shapefile in ArcGIS/ArcInfo 10 suite mostly as point attributes. Each of the seven parameters were assigned ratings and weight according to the SINTACS method employed (Table 2).

\subsection{Interpolation Method}

Geostatistical interpolation methods are stochastic methods, with kriging being the most well-known representative of this category. Kriging methods are gradual, local and may or may not be exact (perfectly reproduce the measured data). Also, they are not by definition set to constrain the predicted values to the range of the measured values.

Similar to the IDW method, kriging calculates weights for measured points in deriving predicted values for unmeasured locations. With kriging, however, those weights are based not only on distance between points, but also the variation between measured points as a function of distance. The kriging process is composed of two parts: analysis of this spatial variation and calculation of predicted values (Baldridge, 2004).

\subsection{Variogram Models}

Variogram analysis consists of the experimental variogram calculated from the data and the variogram model fitting to the data. The experimental variogram is calculated by averaging one half the differences squared of the $\mathrm{z}$ values over all pairs of observations with the specified separation distance and direction. A typical semivariogram/variogram model is made up of the Sill, Range and Nugget. The three most commonly used variogram models are Spherical, Exponential and Gaussian (Anon., 1991).

\section{Results and Discussion}

Parameters constructed from data sets to create the layers and subsequent overlay of the layers to produce the Groundwater Vulnerability Map based on SINTACS parameters are summarised in table 3. Generally, the depth to water in the area is low usually within the range of $1.5 \mathrm{~m}$ to $8.0 \mathrm{~m}$ which gives a range between 27.5 and 47.5 from the SINTACS model.

Effective infiltration in the area was calculated using the recharge index which is the sum of slope $(\%)$, rainfall intensity and soil permeability. The effective infiltration within the area is between 70 $\mathrm{mm} / \mathrm{yr}$ to $299 \mathrm{~mm} / \mathrm{yr}$ and these values were translated into the SINTACS model to give a range between 12 and 36 . Also, the unsaturated condition of the area was analysed from borehole logs and the rocks encounted. They were mainly sandstone, phyllite quartzite, quartz and conglomerate which give a range of values between 20 and 47.5 using the SINTACS model. Silty-sand, silt, laterite and silt sand were the various soil types found in the area and was translated into the SINTACS model to obtain a range between 20 and 28 . Borehole logs also revealed that the rock types found within the aquifer media include weathered phyllite, fractured phyllites and quartzite, sandstone and conglomerate which gives a range of values between 9 and 28.5 using the SINTACS model. With regard to the transmissivity and the thickness of saturated zone, hydraulic conductivity was calculated using pumping test data and the results indicate a range of values between $(0.72-4.0) \times 10^{-6} \mathrm{~m} / \mathrm{s}$. This was translated into the SINTACS model to obtain a range between 6 and 15 (Table 3). The slopes in the area were derived from the DEM and classified according to the criteria of SINTACS model and the values ranges between $10 \%$ and $25 \%$ were translated into the SINTACS model to obtain a range between 4 and 12 (Table 3 ).

\subsection{Water Table Depth}

Deeper static water levels suggest lesser chance of a contaminant to get to the groundwater and vice versa. According to the SINTACS model, it is assumed that contaminants are soluble in water and are usually introduced on the surface of the earth. Therefore, boreholes with shallow depth to water table levels are more vulnerable to contamination than those with deeper depth water table levels. The Birimian, Intrusives and the Tarkwa Phyllites are characterised by high SINTACS index of 47.5, 40.5 and 41 respectively suggesting short travel time for contaminants to get to the groundwater.

Table 2 Weights and Ratings Used for the SINTACS Model (Civita and De Maio, 1997)

\begin{tabular}{|l|c|c|}
\hline SINTACS Parameter & Rating & Weight \\
\hline Water table depth $(\mathrm{m})$ & $1-10$ & 5 \\
\hline Effective infiltration $(\mathrm{mm} / \mathrm{yr})$ & $1-10$ & 4 \\
\hline Unsaturated conditions & $1-10$ & 4 \\
\hline Soil media & $1-10$ & 3 \\
\hline Aquifer hydrogeologic characteristics & $1-10$ & 3 \\
\hline Hydraulic Conductivity $(\mathrm{m} / \mathrm{s})$ & $1-10$ & 2 \\
\hline Topographic slope $(\%)$ & $1-10$ & \\
\hline
\end{tabular}


Table 3 SINTACS Parameters Constructed from Datasets

\begin{tabular}{|l|c|c|c|c|c|c|}
\hline \multirow{2}{*}{ SINTACS Parameters } & \multicolumn{6}{|c|}{ SINTACS Index $\left(\mathbf{P}_{\mathbf{i}} \times \mathbf{W}\right)$ for the rock types in the study area } \\
\cline { 2 - 8 } & $\begin{array}{c}\text { Huni } \\
\text { Sandstone }\end{array}$ & $\begin{array}{c}\text { Tarkwa } \\
\text { Phyllite }\end{array}$ & $\begin{array}{c}\text { Banket } \\
\text { Series }\end{array}$ & $\begin{array}{c}\text { Kawere } \\
\text { Group }\end{array}$ & Birimian & Intrusives \\
\hline Water table depth & 35 & 41 & 35 & 27.5 & 47.5 & 40.5 \\
\hline Effective infiltration & 20 & 24 & 36 & 12 & 26 & 28 \\
\hline Unsaturated conditions & 35 & 20 & 40 & 37.5 & 30 & 47.5 \\
\hline Soil media & 28 & 20 & 22 & 24 & 20 & 16 \\
\hline $\begin{array}{l}\text { Aquifer hydrogeologic } \\
\text { characteristics }\end{array}$ & 12 & 9 & 12 & 15 & 28.5 & 27 \\
\hline Hydraulic conductivity & 11 & 12 & 15 & 6 & 14 & 9 \\
\hline Topographic Slope & 12 & 6 & 4 & 11 & 10 & 12 \\
\hline $\mathrm{I}_{\text {SINTACS }}=\sum_{\mathrm{J}=1}^{7} \mathrm{P}_{\mathrm{J}} \mathrm{W}_{\mathrm{J}}$ & $\mathbf{1 5 3}$ & $\mathbf{1 3 2}$ & $\mathbf{1 6 4}$ & $\mathbf{1 3 3}$ & $\mathbf{1 7 6}$ & $\mathbf{1 8 0}$ \\
\hline
\end{tabular}

The dominant class index of 35 occurred in the Huni Sandstone and the Banket Series. This suggests that in these areas, there is a comparatively longer travel time for contaminants to reach the groundwater. Deeper depth to water was obtained in the Kawere Group rocks and are characterised by "Very Low" SINTACS index of 7.5 which has the longest travel time for contaminants to reach the groundwater (Fig. 4). "Moderate" (35) occurs in the Huni Sandstone and the Banket Series. The Phyllite, Intrusive and Birimian rocks with an index of 41, 40.5 and 47.5 respectively are high.

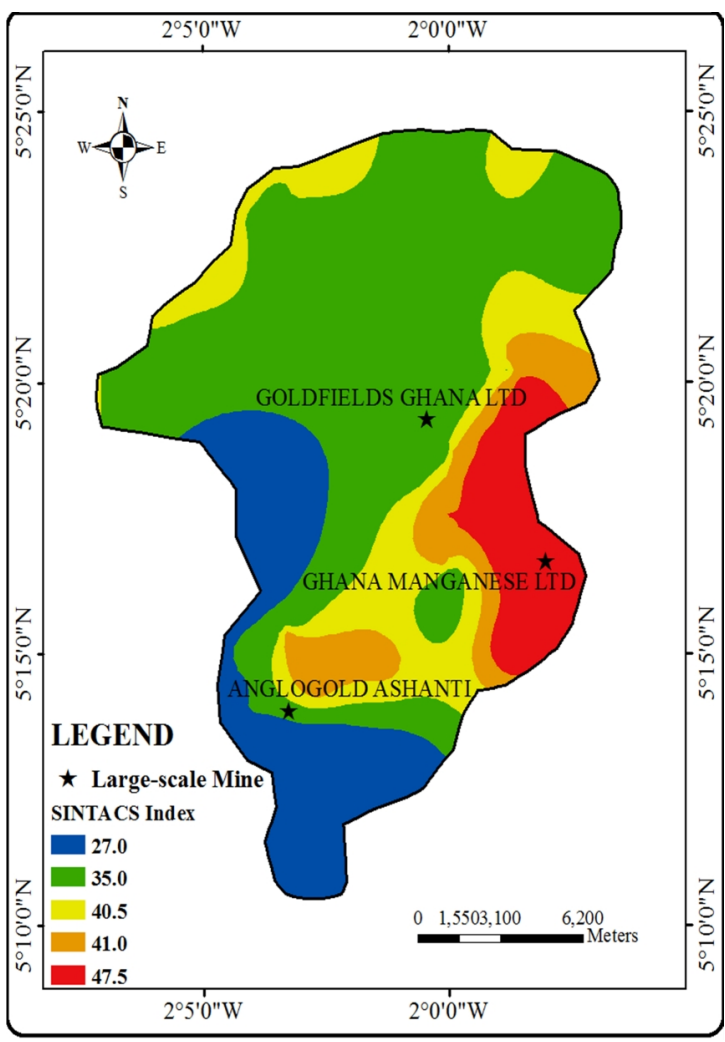

Fig. 4 Map of Depth to Water Table

\subsection{Effective Infiltration}

Effective infiltration represents the amount of water which percolates from the surface to reach the groundwater. Recharge water is the vehicle for transporting pollutants. Although the study area is characterised by relatively high annual rainfall (1 500-1 933) $\mathrm{mm}$ per year, the net recharge to the groundwater aquifer is controlled by the type of landuse or landuse cover. High effective infiltration suggests higher percolation leading to high recharge for precipitation. The Banket Series have higher infiltration capacity of 36 on the SINTACS index as a result of current distortion of landscape and vegetation due to abundant surface mining activities suggesting that there are more pervious surfaces for water with contaminant to percolate to the groundwater. The Phyllite, Birimian and the intrusives have moderate to high effective infiltration with SINTACS index of 24, 26 and 28 respectively which indicates that, there is a moderate pervious surface for water with contaminant to percolate. The Huni Sandstone has a low effective infiltration with a SINTACS index of 20 as a result of abundant vegetation indicating more impervious surfaces and hence less water with contaminant to get to groundwater (Fig. 5).

\subsection{Unsaturated Condition}

It is the unsaturated zone between the soil media and the aquifer media. The texture and permeability of the vadose zone determines the travel time of the contaminant. In the SINTACS model, vadose zone material that holds more water with contaminant has low contamination potential hence longer travel time for contaminants to get into the groundwater and vice versa. The decreasing order of vulnerability is sand, granites, phyllites, siltstone and clay. The high SINTACS index classes of 47.5 occur within the jointed and fractured Intrusives. The Kawere Group which are underlain by the conglomerates, Banket Series and the Huni Sandstone has moderate to high SINTACS index classes of $37.5,40$ and 35 
respectively with gravel, sand and silt as their weathering product which has a high draining ability and hence short travel time for contaminants to reach the groundwater. The Birimian and the Tarkwa Phyllite have low SINTACS index classes of 30 and 20 respectively with weathering product silt and clay which has low draining abilities and thus, high capacity to hold water and contaminants resulting to longer travel time (Fig. 6).

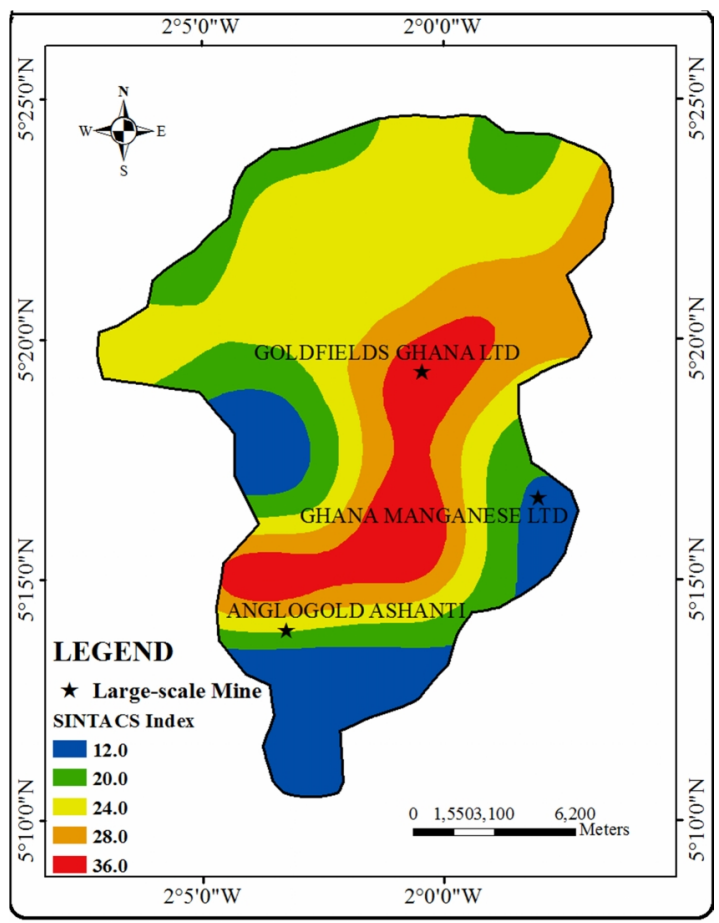

Fig. 5 Map of Effective Infiltration

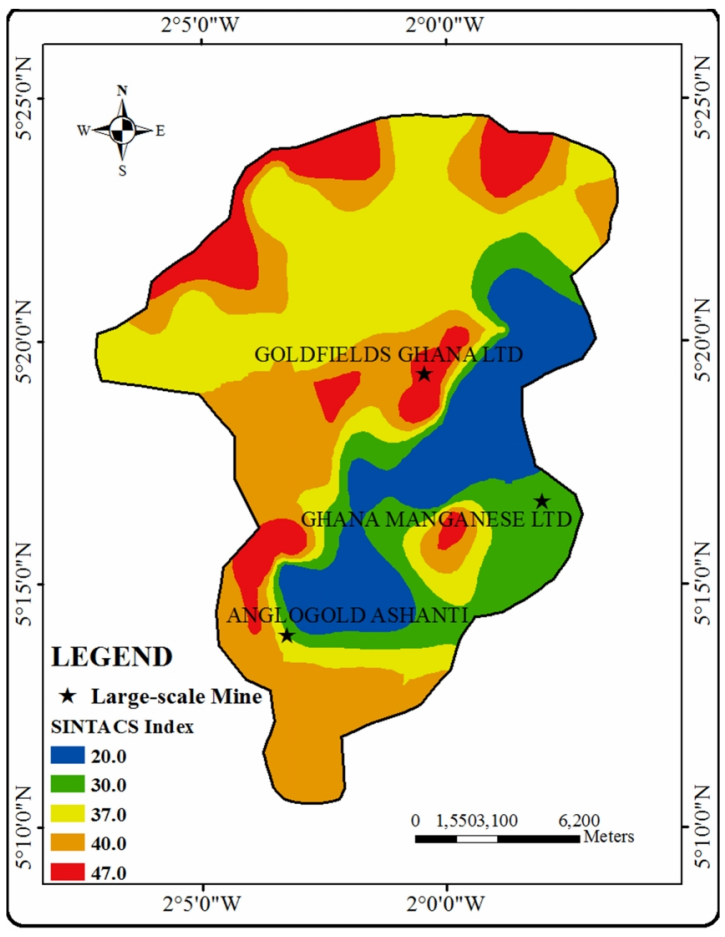

Fig. 6 Map of Unsaturated Condition

\subsection{Soil Media}

Groundwater vulnerability is controlled by the textural properties of soil. The most predominant soils are the clay, silt, laterite and sand. Sandy materials have grain sizes larger than silty materials. The draining ability of sandy materials is more than the silty materials which have finer grain sizes. Laterite is the combination of silt, clay and some aggregation of gravels of ferricrete nodules. Therefore, the degree of increasing vulnerability would be as follows; sand, laterite, silt and clay. A map produced using data on the characteristics of the soil media (Fig. 7) show that, the Huni Sandstone and the Kawere Group are predominantly characterised by high SINTACS index classes of 28 and 24 respectively as a result of the presence of silty-sand overburden. Areas with laterite have medium to low SINTACS index classes of 20 to 24 occurring within the Tarkwa Phyllite, Birimian and the Banket Series. The Intrusive rocks have low SINTACS index class of 16 as a result of the presence of silt.

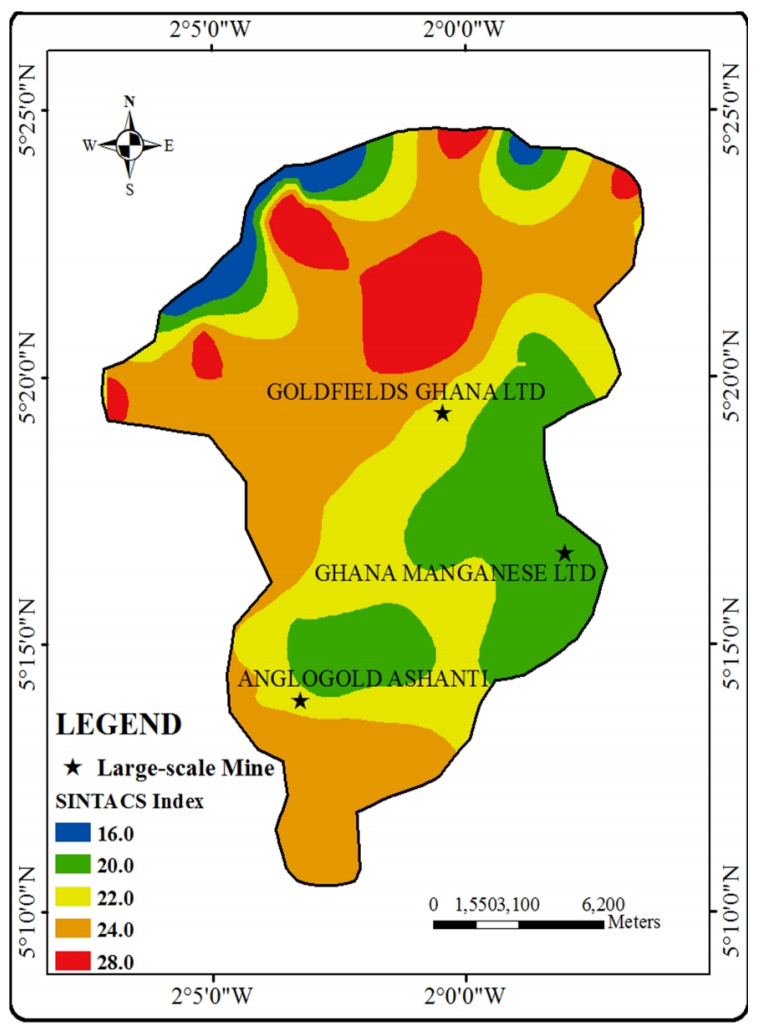

Fig. 7 Map of Soil Media

\subsection{Aquifer Hydrogeological Characteristics}

The aquifers in Tarkwa occur in the Tarkwaian and the Birimian which is predominantly weathered phyllites, fractured quartzite and intrusives, sandstones, conglomerate and quartz. Both fresh phyllites and quartzite have low porosity (Fetter, 1994). Few pores present are small and are generally not interconnected and therefore have low permeability. Phyllites and quartzite can bear 
water because of their secondary porosity that result from weathering, fracturing and shearing. The high to moderately high SINTACS index classes of 27 and 28.5 occur within the Birimian and the Intrusive rocks hence short travel time for contaminants to travel to the groundwater. Areas which are characterised by medium to low SINTACS index classes between 9 and 15 (Fig. 8) are underlain by conglomerates, sandstone with fresh and weathered phyllites and quartzites which have low permeability and hence long travel time for contaminants to reach the groundwater.

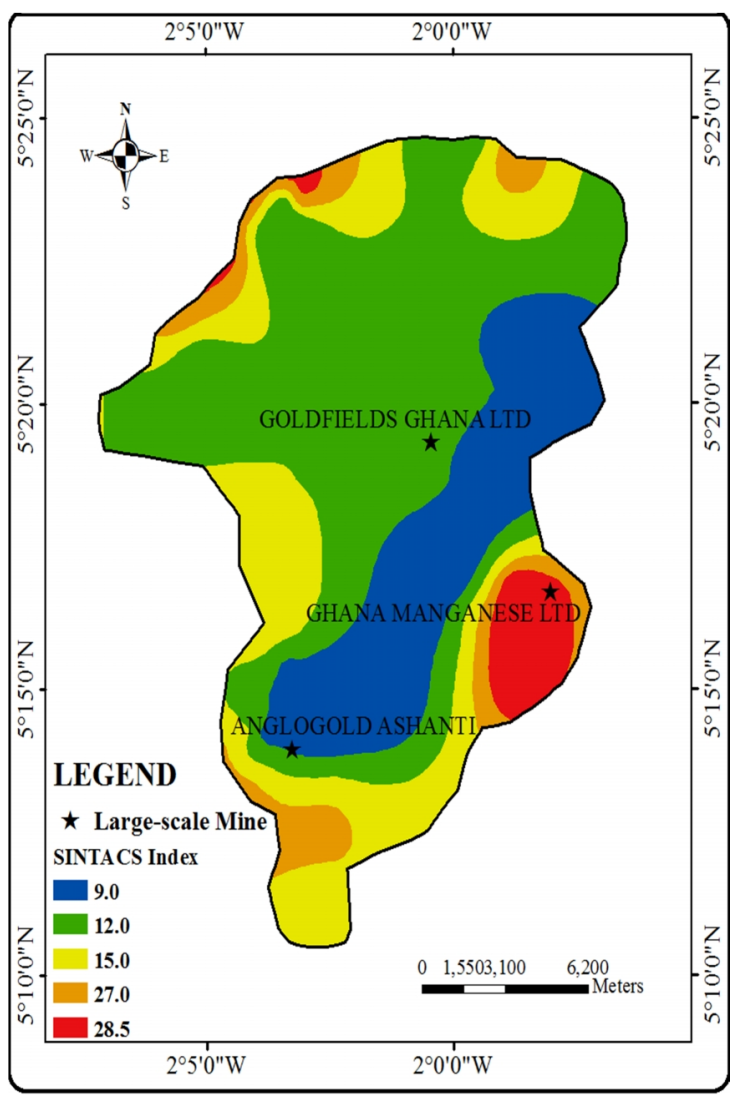

Fig. 8 Map of Aquifer Hydrogeological Characteristics

\subsection{Hydraulic Conductivity}

The Hydraulic conductivity refers to the rate at which water flows through an aquifer. The hydraulic conductivity in the study area ranged between $0.72 \times 10^{-6} \mathrm{~m} / \mathrm{s}$ and $4.0 \times 10^{-6} \mathrm{~m} / \mathrm{s}$. In the SINTACS model, it gives the ease at which the aquifer will transmit water with the contaminant in the aquifer medium. Therefore, the higher the hydraulic conductivity, the higher the vulnerability to contamination.

Weathered quartzites are more permeable than the weathered phyllites. Therefore, hydraulic conductivity in the weathered quartzites is higher than that of the weathered phyllites. This is because, the weathering product of quartzite is predominantly sand which has a higher permeability than phyllites who's weathering products are predominantly clay and silt. Hence, the Banket Series and the Birimian have high SINTACS index class of 15 and 14 respectively which occupies most of the surface mining environment. Medium SINTACS index class of 11 and 12 are obtained within the Huni Sandstone and the Tarkwa Phyllite respectively. The Kawere Goup and the Intrusives have low SINTACS index classes of 6 and 9 respectively which is as a result of silt being the weathering products (Fig. 9).

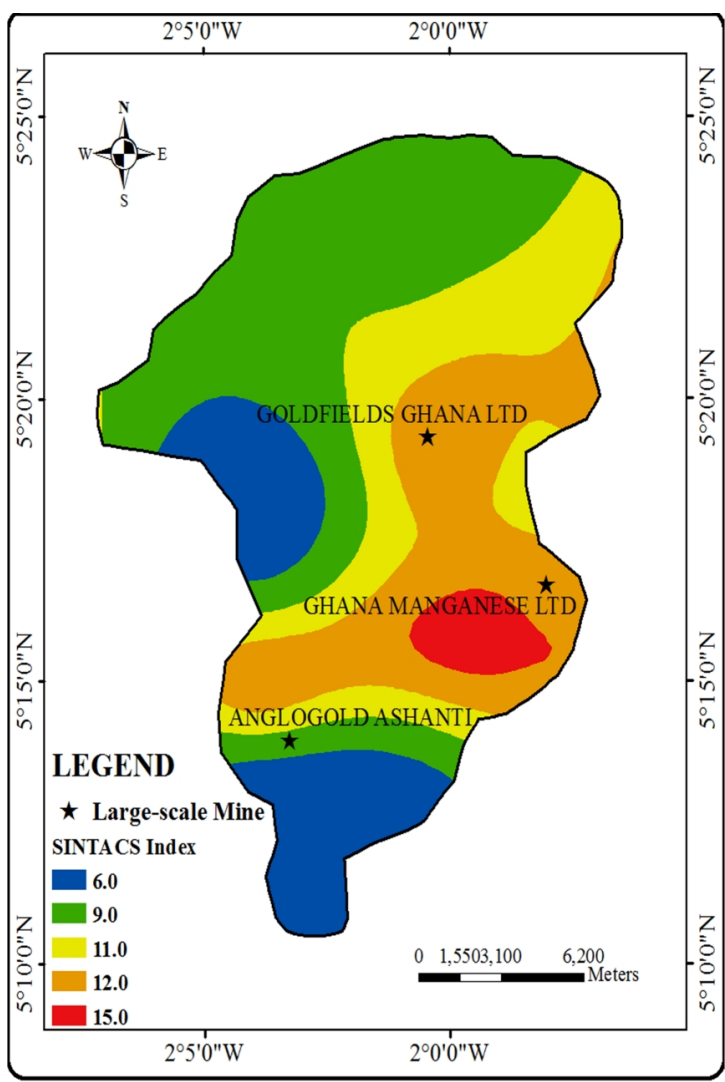

Fig. 9 Map of Hydraulic Conductivity

\subsection{Topographic Slope}

Topography refers to the slope of the land surface. In the SINTACS model, high slope percentages increase the run-off and thereby decreasing vulnerability. The low percentage slope indicates a decrease in run-off and the subsequent retention of contaminant and hence high vulnerability.

High SINTACS index classes between 10 and 12 occurs within the Birimian rocks, Intrusive rocks, Huni Sandstone and the Kawere Conglomerate which are characterised by low topographic slope. The moderate to low SINTACS index classes of 4 and 6 occur in areas characterised by hilly terrain which corresponds to high net recharge and are generally underlain by the Banket Series and the Tarkwa phyllite respectively (Fig. 10). 


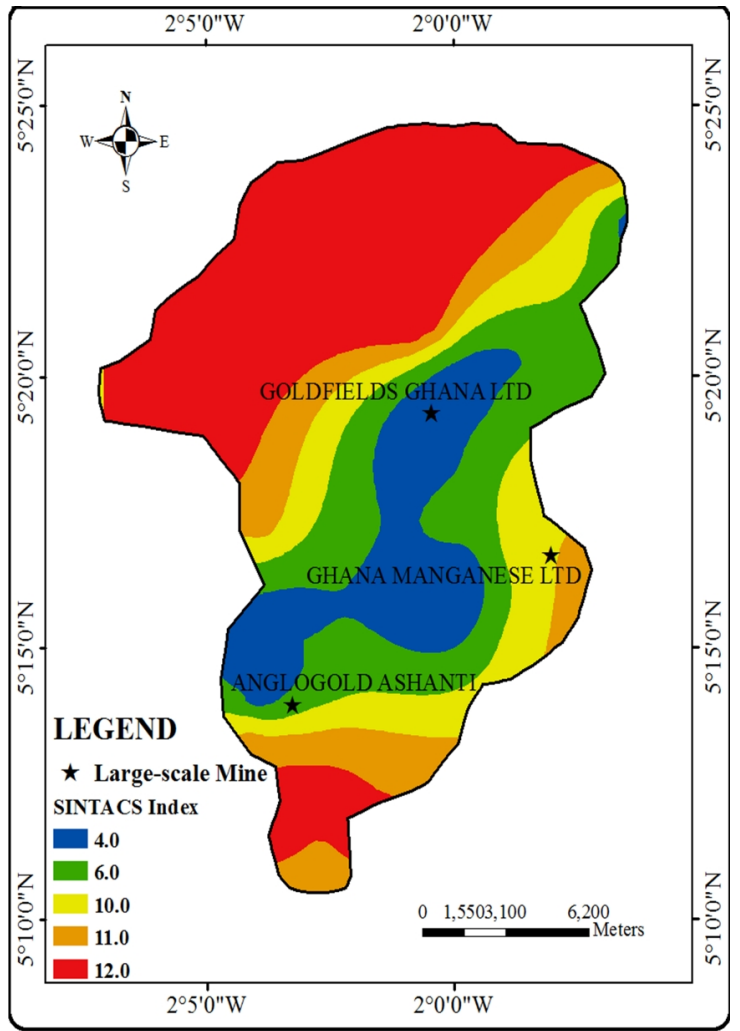

Fig. 10 Map of Topographic Slope

\subsection{Overlay Analysis of the SINTACS Parameters}

GIS Arc Map 10.1 was used to overlay the seven SINTACS raster layers to produce the Groundwater Vulnerability Map of Tarkwa. The original SINTACS classes of intrinsic vulnerability by Civita and De Maio (1997) gives the following classification as shown in Table 4.

Table 4 Classes of Intrinsic Vulnerability (Civita and De Maio, 1997)

\begin{tabular}{|c|c|}
\hline SINTACS index & Degree of vulnerability \\
\hline $26-80$ & Very Low \\
\hline $80-105$ & Low \\
\hline $105-140$ & Medium \\
\hline $140-186$ & High \\
\hline $186-210$ & Very High \\
\hline $210-260$ & Extreme \\
\hline
\end{tabular}

The resulting SINTACS vulnerability index obtained for this study has a minimum value of 131 and a maximum value of 180 . These values have therefore been modified to classify into the following ranges on the basis of the original SINTACS classification as shown in Table 5. The modified SINTACS vulnerability classes were subsequently used to produce the Groundwater Vulnerability Map of the area (Fig. 11).
Table 5 SINTACS Vulnerability Classes Constructed from Data Set

\begin{tabular}{|c|c|}
\hline SINTACS index & Degree of vulnerability \\
\hline $130-145$ & Medium \\
\hline $145-160$ & Moderately High \\
\hline $160-175$ & High \\
\hline $175-180$ & Very High \\
\hline
\end{tabular}

The groundwater vulnerability to contamination map produced showed four vulnerability classes of "Medium", "Moderately High", "High" and "Very High" as shown in Fig. 11.

The vulnerable zones characterised by "Medium" index are mainly dictated by the geology and are located mainly within the Tarkwa Phyllite and the Kawere Group. The rock units are predominantly Phyllite and Conglomerate. These rock types affect the soil media, vadose zone impact, aquifer media and the hydraulic conductivity. The primary porosity of the Phyllites is generally very low. They are able to bear water because of secondary permeability by fractures and weathering. The vadose zone was observed to have been mostly fractured which increases secondary permeability. The travel time for contaminants is minimal and hence "Medium" vulnerability index in these areas.

The fresh quartzites and conglomerates within the Banket Series have very low primary porosity. Aquifers within the quartzites produce water because of the fractures and weathering. The weathering product is mostly sand which has a very high draining capabilities. The soil and the vadose zone would allow more water with contaminants to seep into the aquifer media. This indicates a high net recharge in these zones and is highly vulnerable as net recharge is the carrier of most contaminants into groundwater.

The high draining abilities of the soil and the vadose zone, high net recharge couple with low slope percentages are responsible for the vulnerable zones of "Moderately High" and "High" classes in the Huni Sandstone and the Banket Series respectively.

Finally, the vulnerable zones characterised by "Very High" index are mainly within the Birimian and the Intrusive rocks. The rock units in these vulnerable zones are predominantly fractured phyllites and quartz, sills and dykes of igneous rocks ranging from felsite and quartz porphyry to meta-dolerite. The type of rock units affects the soil media, vadose zone impact, the aquifer media and the hydraulic conductivity. The depth to water table within the Birimian is general low $(1.5 \mathrm{~m})$ with 
short travel time by contaminants. The porosity of the Birimian intrusives is generally high. They are able to bear water because of abundant fractures and joints which make them highly permeable.

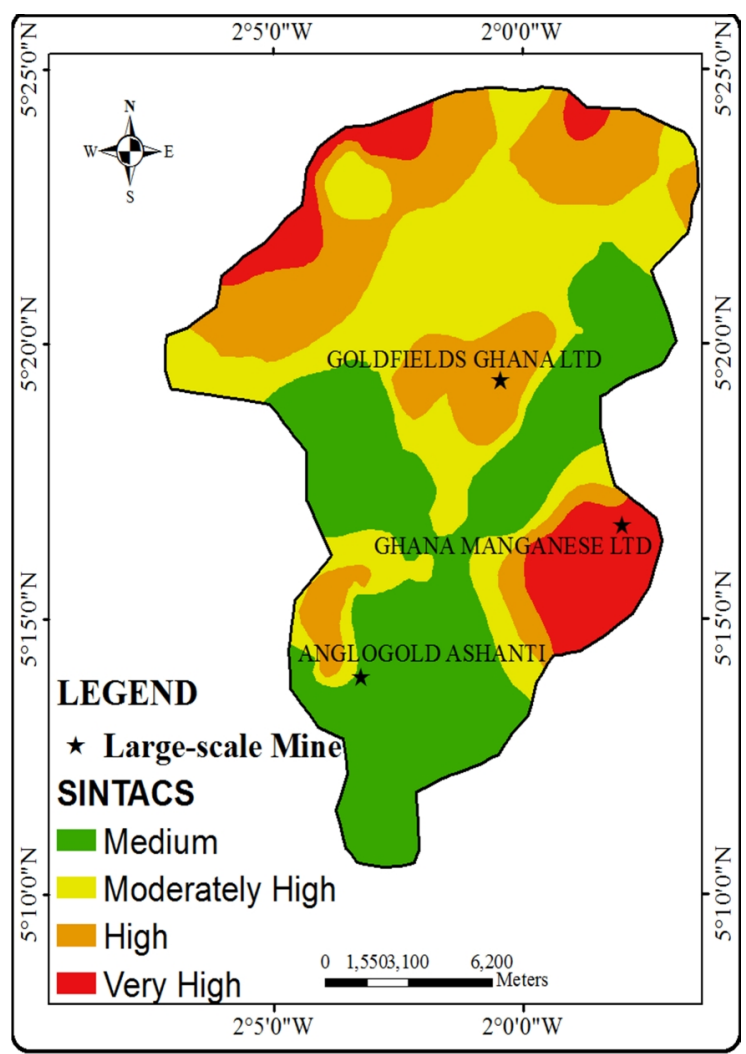

Fig. 11 Groundwater Vulnerability Map of Tarkwa Mining Area

The vadose zone was observed to have been mostly fractured and jointed which increases secondary permeability. Net recharge which is the carrier of most contaminants into groundwater is generally high within the intrusives due to the gentle topographical nature of the area which results into low runoff and hence "Very High" vulnerability class. The vulnerability index and the degree of vulnerability of the rocks in the Tarkwa area have been summarized in Table 6 .

Table 6 SINTACS Vulnerability Index

\begin{tabular}{|l|l|l|}
\hline Rock Type & I $_{\text {SINTACs }}$ & $\begin{array}{l}\text { Degree of } \\
\text { vulnerability }\end{array}$ \\
\hline Huni Sandstone & 153 & Moderately High \\
\hline Tarkwa phyllite & 132 & Medium \\
\hline Banket Series & 164 & High \\
\hline Kawere Group & 133 & Medium \\
\hline Birimian & 176 & Very High \\
\hline Intrusives & 180 & Very High \\
\hline
\end{tabular}

\subsection{Variogram Analysis}

From Geostatistical analysis, it is necessary to replace the empirical variograms with appropriate models. In this study, different variogram models were tried to fit to the experimental variogram of each SINTACS parameter.

The directional variogram and exploratory data analysis suggested that most of the SINTACS parameters are anisotropic and they have major and minor ranges. Cross-validation was used in the determination of which model provides the best predictions. The spherical and the exponential model gave the best fit and their corresponding lag size, nugget value, sill and spatial dependency are presented in table 7 .

The ratio of nugget to sill variances, expressed as percentage, can be regarded as a criterion to classify the Spatial Dependency of the SINTACS parameters. If the ratio is less than 0.25 , the variance has strong spatial dependency and if the ratio ranges between 0.25 and 0.75 , the variance has moderate spatial dependency. Table 7 suggest that, all parameters used in the SINTACS model have a strong spatial structure with its spatial dependency ranging from 0.00 to 0.23 .

\subsection{Statistical Analysis of the SINTACS Model}

The statistical summaries, of the seven hydrogeological parameters calculated using the SINTACS index, are shown in Table 8. One parameter (depth to groundwater) shows high vulnerability degree with mean value more than 7 . However, hydraulic conductivity and topographic slope reveal low risk aquifer contamination with mean values 3.67 and 4.58 respectively; while effective infiltration, unsaturated condition, soil media and aquifer hydrogeological characteristics show moderate vulnerability level with mean values of $6.17,7.0,5.58$ and 5.58 respectively.

Table 8 show aquifer hydrogeological characteristics with highest variable value of $46.16 \%$. Soil media and depth to groundwater have the lowest variable value $14.35 \%$ and $17.89 \%$ coefficient of variation (CV) respectively. Effective infiltration $33.10 \%$ and topographic slope $36.78 \%$ represent moderate variable, while unsaturated condition $26.73 \%$ and hydraulic conductivity $29.46 \%$ are low variable parameters. 
Table 7 Results of the Variogram Model obtained for each SINTACS Parameter

\begin{tabular}{|c|l|c|c|c|c|}
\hline Parameter & Model Fitted & Lag Size & Nugget & Sill & Spatial Dependency \\
\hline S & Exponential & 1866.90 & 0.013 & 0.31 & 0.04 \\
\hline I & Spherical & 391.50 & 0.006 & 0.08 & 0.08 \\
\hline N & Exponential & 564.35 & 0.037 & 0.50 & 0.07 \\
\hline T & Spherical & 383.79 & 0.005 & 0.13 & 0.04 \\
\hline A & Exponential & 1094.57 & 0 & 0.35 & 0.00 \\
\hline C & Spherical & 737.03 & 0.048 & 0.21 & 0.23 \\
\hline S & Exponential & 358.12 & 0 & 0.21 & 0.00 \\
\hline
\end{tabular}

Table 8 Statistical Summary of the SINTACS Parameters

\begin{tabular}{|c|c|c|c|c|c|c|c|c|}
\hline Parameter & $\begin{array}{c}\text { Theoretical } \\
\text { Weight }\end{array}$ & Min & Max & Mean & $\begin{array}{c}\text { Theoretical } \\
\text { Weight } \\
\mathbf{( \% )}\end{array}$ & $\begin{array}{c}\text { Effective } \\
\text { Weight } \\
(\%)\end{array}$ & Std. Dev. & CV (\%) \\
\hline S & 5 & 5.5 & 9.5 & 7.5 & 19.2 & 19.7 & 1.34 & 17.89 \\
\hline I & 4 & 3 & 9 & 6.17 & 15.4 & 16.2 & 2.04 & 33.10 \\
\hline N & 5 & 4 & 9.5 & 7.0 & 19.2 & 18.4 & 1.87 & 26.73 \\
\hline T & 4 & 5 & 7 & 5.58 & 15.4 & 14.7 & 0.80 & 14.35 \\
\hline A & 3 & 3 & 9.5 & 5.58 & 11.5 & 14.7 & 2.58 & 46.16 \\
\hline C & 3 & 2 & 5 & 3.67 & 11.5 & 9.6 & 1.08 & 29.46 \\
\hline S & 2 & 2 & 6 & 4.58 & 7.7 & 12.0 & 1.62 & 36.78 \\
\hline
\end{tabular}

\subsection{Sensitivity analysis of the SINTACS Model}

The single parameter sensitivity analysis is designed to compare their "theoretical" weights with that of "effective" weights. The effective weights of the SINTACS parameters exhibited some deviation from those of the theoretical weights as shown in Fig. 12. This deviation is less significant since the standard deviations of all the parameters is less than 5 .

Table 8 reveal that the depth to water table, effective infiltration, aquifer media and topographic slope tend to be the most effective parameters in the vulnerability assessment because their mean effective weights, $19.7 \%, 16.2 \%$, $14.7 \%$ and $12.0 \%$ respectively, are higher than their respective theoretical weights.

Unsaturated condition, soil media and hydraulic conductivity show a low effective weight compared to the theoretical weight. The lowest effective weight was net recharge $(9.6 \%)$ compared to its theoretical weight $(11.5 \%)$. This shows the importance of depth to water table, effective infiltration, aquifer media and topographic slope layers in the SINTACS model. The calculated effective weights for each parameter is comparable to the theoretical weights assigned in SINTACS model (Fig. 12). This Suggests that accurate information were used for the study. Therefore, the effective weight analysis is very useful to revise the weight factors so that the SINTACS model may be applied more scientifically to address local issues and represent the local hydro-geological settings.

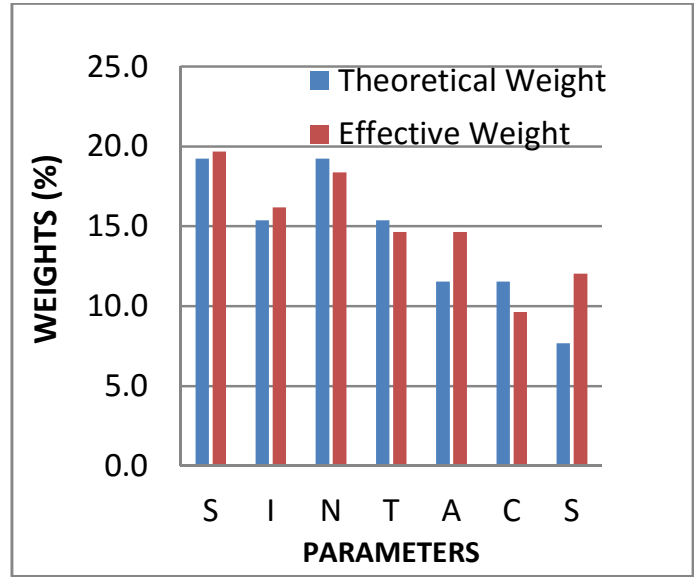

Fig. 12 Graphical Representation of the Mean Rating for the SINTACS Parameter

\section{Conclusions}

The groundwater vulnerability to contamination map produced showed four vulnerability classes of Medium, Moderately High, High and Very High. The vulnerability zones characterised by Medium class is underlain by the Tarkwa Phyllite and the Kawere Group. Moderately High vulnerability class is located within the Huni Sandstone. High vulnerability class is located within the Banket Series. The vulnerability zones characterised by Very High class is located in the Birimian and the Intrusive rocks. Therefore, boreholes drilled in the fractured and jointed Birimian and Intrusive rocks are more vulnerable or highly susceptible to contamination than those drilled in the Huni Sandstone, Banket Series, Tarkwa Phyllites and the Kawere Group. Analysis from the variogram model shows that, all parameters used in the SINTACS 
model have a strong spatial distribution. From the statistical analysis, depth to groundwater is the most sensitive parameter with mean value more than 7. The single-parameter sensitivity analysis prodused standard deviations less than 5.0 which shows that accurate information was used for the study. The GIS technique provided an efficient environment for analysing the data.

\section{References}

Akabzaa, T. M. (2000), Boom and Dislocation "The Environmental and Social Impacts of Mining in the Wassa West District of Ghana", Third World Network-Africa, pp. 17-22.

Akabzaa, T. and Darimani, A. (2001), Impact of mining sector investment in Ghana, A study of the Tarkwa mining region, Draft Report for SAPRI, Accra, Ghana, pp. 29-30.

Anon. (2010), "Mining operations violate right of mining communities to clean waterWacam ",http://mobile.ghanaweb.com/wap/arti cle.php?ID=178917.Accessed: February 10, 2016.

Anon. (1991),"VariogramTutorial.GoldenSoft.Inc”, http://www.goldensoftware.com/variogramTuto rial.pdf. Accessed: February 28, 2017.

Baldridge, E. (2004), Developing Spatially Interpolated Surfaces and Estimating Uncertainty. U.S. Environmental Protection Agency, Office of Air and Radiation, Office of Air Quality Planning and Standards, Original Research Article, pp. 49-73.

Cività, M. and De Maio, M. (1997), "SINTACS: Un sistema parametrico per la valutazione e la cartografia della vulnerabilita degli acquiferi all'inquinamento", Metodologia \& automAti zzazione. Bologna, Pitagora Editrice, 208 pp.

Eisenlohr, B. N. and Hirdes, W. (1992), "The structural development of the early Proterozoic Birimian and Tarkwaian rocks of South west Ghana, West Africa", Journal of African Earth Sciences, Vol. 14, No. 3, pp. 313325.

Fetter, C. W. (1994), Applied Hydrogeology, $2^{\text {nd }}$ edition, Macmillan College Publishing Company, New York, NY, 615 pp.

Junner, N. R., Hirst, T. and Service, H. (1942), "The Tarkwa Goldfield". Gold Coast Geological Survey, Memoir, No. 6, pp. 48-55.

Kesse, G. O. (1985), The Mineral and Rock Resources of Ghana, A. A. Balkema Publishers, Rotterdam, $610 \mathrm{pp}$.

Kortatsi, B. K. (2002), "Hydrochemistry of groundwater in the mining area of TarkwaPrestea, Ghana", Ph.D. Thesis, University of Ghana, pp. 70-85.

Kuma, J. S. (2007), "Hydrogeological studies in the Tarkwa Gold Mining District, Ghana", Bulletin of Engineering Geology and the Environment 66, pp. 89 - 99.
Kuma, J. S. and Younger, P. L. (2001), "Pedological characteristics related to groundwater occurrence in the Tarkwa area, Ghana", J. Afr. Earth Sci., Vol. 3, No. 33, pp. 363-376.

Naicker, K., Cukrowska, E. and McCarthy, T. S. (2003), Acid mine drainage arising from gold mining activity in Johannesburg, South Africa and environs, Vol. 122, pp. $29-40$.

Smedley, P. L., Edmunds, W. M., West, J. M., Gardner, S. J. and Pelig K. B. (1995), Health problems related to groundwater in the Obuasi and Bolgatanga areas, Ghana. British Geological Survey, Technical Report, $\mathrm{WC} / 95 / 43,122 \mathrm{pp}$.

Tazioli, G. S., Cantori, P. M. and Ciancetti, G. F. (1995), "Inter-comparison of different tracers in the evaluation of groundwater dynamics in heterogeneous porous aquifers", IAEA-SM 336/40, Vienna, 147 pp.

Yankey, R. K., Akiti, T. T., Osae, S., Fianko, J. R., Duncan, A. E., Amartey, E. O., Essuman, D. K. and Agyemang, O. (2011), "Research Journal of Environmental and Earth Sciences", Vol. 3, No. 5, pp. 600-607.

\section{Authors}

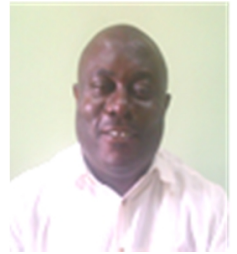

A. Ewusi holds a PhD Hydrogeophysics and an $\mathrm{MSc}$ in Environmental Hydrogeology from the Brandenburg University of Technology, Germany. He obtained a BSc (Hons) Geological Engineering from the Kwame Nkrumah University of Science and Technology (KNUST), Kumasi, Ghana. He Lectures in Geophysics and Hydrogeology. His research interests are in groundwater management and geophysics.

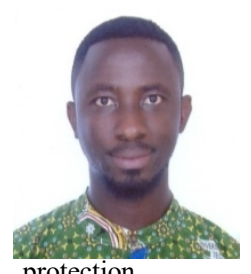

protection.

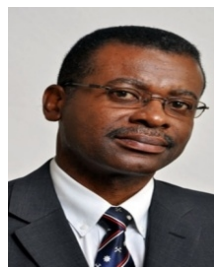

I. Ahenkorah holds BSc in Geological Engineering from the University of Mines and Technology (UMaT), Tarkwa, Ghana. His areas of research include groundwater resources management and protection, hydrogeology and geophysics, GIS and integrated software application in groundwater resources management and

J. S. Y. Kuma is a Professor in Environmental Hydrogeology and Geophysics at the University of Mines and Technology (UMaT), Tarkwa. He was awarded a BSc (Hons) in Geology and Physics at the University of Ghana, Legon. He received the Pg Dip and MSc degrees in Geophysics at Delft, The Netherlands. Professor Kuma received a $\mathrm{PhD}$ in Water Resources Engineering from the University of Newcastle upon Tyne, England. He is currently actively involved in mine water hydrogeological research and water management issues. 